\title{
Mucosal vitiligo in angles of the mouth: clinical and fluorescence aspects
}

\author{
DSérgio Araújo Andrade \\ Isabela Guimarães Ribeiro Baeta² \\ (iD) Marisa Maria Ribeiro 3 \\ iD Sebastião Pratavieira \\ DVanderlei Salvador Bagnato 4 \\ (iD) Fernando de Pilla Varotti ${ }^{1}$
}

1. Research Center on Biological Chemistry (NQBio), Federal University of São João del-Rei (UFSJ), Divinópolis, MG, Brasil 2. Adjunct Professor of Dermatology, Federal University of São João del-Rei (UFS|), Divinópolis, MG, Brasil 3. Oral Diagnosis Center of the Divinopolis Health Department, Divinópolis. MG, Brasil 4. Physics Institute of São Carlos of the University of São Paulo (IFSC-USP), São Carlos, SP. Brasil

http://dx.doi.org/10.1590/1806-9282.65.3.330

\section{SUMMARY}

Vitiligo is the most common depigmenting, chronic acquired disease of the skin and mucosa. However, vitiligo of an unclassified type and mucosal subtype affecting only one area of the mucosa is considered quite uncommon. The diagnosis of vitiligo, regardless of its type, is clinical. Nonetheless, a device that allows the visualization of the tissue fluorescence may be useful for confirming the diagnosis. We present the use of wide-field optical fluorescence device for complementary examination and diagnosis of unusual cases of mucosal vitiligo located only in angles of the mouth.

KEYWORDS: Vitiligo. Diagnostic imaging. Diagnosis. Fluorescence. Pathology. Mouth.

\section{INTRODUCTION}

Vitiligo is an acquired chronic disease of the skin or mucosa characterized by the progressive loss of melanocytes and resulting in the reduction or absence of melanin in the affected site ${ }^{1-3}$. The estimated prevalence of vitiligo worldwide is of 0.5 to $1 \%$, and it is considered the most common depigmenting disorder ${ }^{1,2}$. However, vitiligo of an unclassified type and mucosal subtype affecting only one area of the mucosa represents only $2.3 \%$ of the total cases of vitiligo; therefore, a quite uncommon condition ${ }^{4}$.

Clinically, the lesion presents itself as white patches that cannot be removed by scraping1. Thus, although vitiligo is not a fatal disease, the presence of facial lesions may cause aesthetic impairment affecting patients psychosocial aspects, $1,2,4$.
The treatment of vitiligo in the oral region may involve immunomodulators, micropigmentation, phototherapy, and invasive surgical treatments ${ }^{1,4}$. However, vitiligo in the oral region is resistant to treatment; therefore, the early diagnosis contributes to both treatment success and reduction of aesthetic damage ${ }^{4}$.

The diagnosis of vitiligo, regardless of its type, is clinical ${ }^{1,2,4}$. However, it can also be confirmed by examination with devices that allow visualizing the tissue fluorescence ${ }^{1-5}$. In this sense, the diagnosis of vitiligo is confirmed by the visualization of an increase in fluorescence in the region of the lesions due to the lack of absorption of light by melanin caused by the reduction of melanocytes ${ }^{1-4}$. Otherwise, in adjacent 
healthy tissues with the presence of melanin, the fluorescence is reduced ${ }^{5}$.

We present the use of a wide-field optical fluorescence device for complementary examination and diagnosis of an uncommon case of mucosal vitiligo located only in angles of the mouth.

\section{METHODS}

The patient was attended at the Oral Diagnosis Center of the Divinopolis Health Department through a partnership with the Federal University of São João del Rei (Divinópolis, Minas Gerais, Brazil). The protocol consisted of a clinical examination and, in the same consultation, the patient was submitted to the wide-field optical fluorescence complementary examination using the Evince ${ }^{\circledR}$ device (MMOptics, São Carlos, Brazil), which, emits light at a wavelength of $400 \pm 10 \mathrm{~nm}$.

This study has been approved by the Ethics Committee of the Federal University of São João del-Rei, Dona Lindu Center-West Campus (CAAE: 59621516.8.0000.5545; Approval number: 1.756.617).

\section{CASE}

A 55-year-old man with a history of white patches located bilaterally at the angles of the mouth was referred by a general dental practitioner for an oral diagnosis consultation. The diagnostic hypothesis by the general dental practitioner was angular cheilitis. In anamnesis, the patient reported that he noticed the whitish lesions about 3 years ago, which aesthetically bothered him. In addition, the patient reported that the lesions were always painless, without ulcerations or crusts and with a history of unsuccessful treatment with topical corticosteroids and antifungals. There was no report of any disease or family history of autoimmune diseases or vitiligo.

In the general physical examination, no other patches or disorders were observed. During the clinical examination, the presence of whitish patches, bilaterally, on the angles of mouth was observed (Figure 1). The lesions observed with an open mouth were 20 $\mathrm{mm} \times 4 \mathrm{~mm}$ on the right side (Figure 2A) and $20 \mathrm{~mm}$ x $9 \mathrm{~mm}$ on the left side (Figure 2B). The white patches could not be scraped off with gauze and exhibited similar consistency to the adjacent healthy tissue.

In the same medical appointment, during the wide-field optical fluorescence examination, a bright green appearance was observed in the region of the lesions, bilaterally at the angles of the mouth, which is characteristic of increased local fluorescence (Figures 2C, 2D).

Based on the clinical examination and the presentation under fluorescence, the final diagnosis was es-

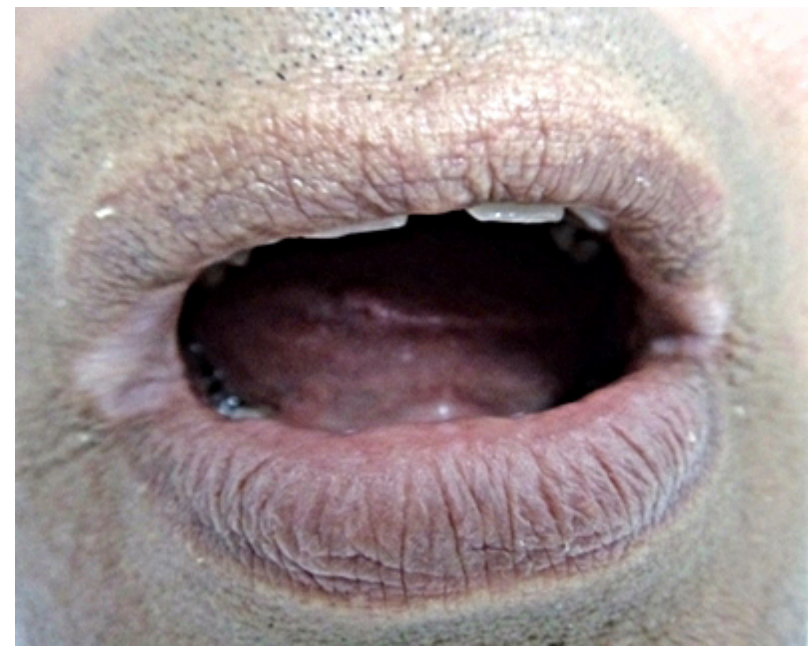

FIGURE 1 Clinical presentation of mucosal vitiligo with the presence of whitish patches bilaterally at the angles of the mouth.
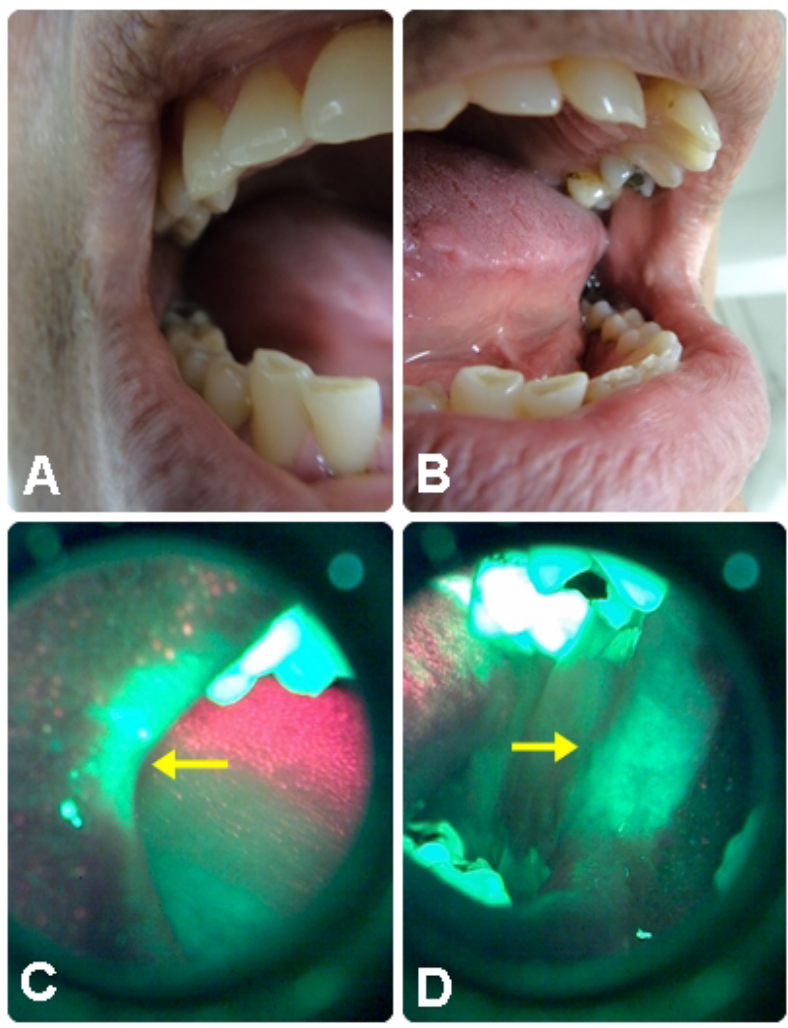

FIGURE 2 Clinical presentation of mucosal vitiligo with the presence of whitish patches at the angle of the mouth on the right side (A) and the left side (B). Wide-field optical fluorescence presentation of mucosal vitiligo; the yellow arrows indicate the increase of bright green fluorescence at the angles of the mouth on the right $(C)$ and left(D). 
tablished as vitiligo. The vitiligo was categorized as an unclassified type and mucosal subtype since the patient presented the lesions only in the region of the angle of the mouth without affecting other areas of the body, and the lesions had been persistent for 3 years. Thus, the patient was referred to a dermatologist for treatment.

\section{DISCUSSION}

This case of unclassified or undetermined type and mucosal subtype of vitiligo is considered quite unusual since, according to the Vitiligo Global Issues Consensus Conference, to receive such classification, the vitiligo lesion, must occur only in the oral mucosa area, for a time longer than 2 years and without the lesions anywhere else on the body ${ }^{2,4}$. Furthermore, according to Prasad ${ }^{4}$, vitiligo lesions usually affect the lip vermilion without extending across the wet labial mucosa. This makes this case even more unusual because when observing the lesion on the left side of the mouth it is observed, both clinically and by fluorescence, that the lesion extends to the wet labial mucosa (Figures 2B,2D).

The general dental practitioner probably considered the hypothesis of angular cheilitis because it is one of the most prevalent oral lesions affecting the oral angle. Moreover, Park et al. ${ }^{6}$ described that in its early stages, angular cheilitis presents as a greyish white thickening at the angles of the mouth. However, this hypothesis was immediately discarded due to the persistence of the lesion for 3 years with treatment failure, consistency of the lesion similar to the adjacent tissue, absence of pain, ulceration, and crusts, which are incompatible with angular cheilitis. It is noteworthy that, during clinical examination, many oral pathologies exhibit similar clinical features making diagnosis difficult $t^{7-9}$.

Thus, to increase the perception of oral lesions, which, could be imperceptible upon clinical examination, the technology of wide-field fluorescence has been approved by the United States Food and Drug Administration (FDA) for use as a complementary examination $^{8-10}$. In summary, we concluded that in this case report wide-field optical fluorescence was a useful complementary examination, as it confirmed the diagnosis of vitiligo through the visualization of an increase in fluorescence caused by the reduction of melanin in the vitiligo area, which, was imperceptible in the conventional clinical examination.

\section{ACKNOWLEDGMENTS}

The authors would like to thank FAPESP and CNPq for their support in the CEPID and INCT programs.

\section{RESUMO}

O vitiligo é a doença crônica adquirida despigmentante mais comum da pele elou da mucosa. Entretanto, o vitiligo do tipo não classificado e subtipo de mucosa afetando apenas uma área da mucosa é considerado bastante incomum. O diagnóstico de vitiligo, independentemente do seu tipo, é clínico. No entanto, o uso de um dispositivo que permite a visualização da fluorescência tecidual pode ser útil para a confirmação do diagnóstico de vitiligo. Apresentamos o uso do dispositivo de exame complementar de fluorescência óptica de campo amplo para o diagnóstico de um caso incomum de vitiligo de mucosa localizado apenas em ângulos da boca.

PALAVRAS-ChAVE: Vitiligo. Diagnóstico por imagem. Diagnóstico. Fluorescência. Patologia. Boca.

\section{REFERENCES}

1. Picardo M, Dell'Anna ML, Ezzedine K, Hamzavi I, Harris JE, Parsad D, et al. Vitiligo. Nat Rev Dis Primers. 2015;1:15011.

2. Ezzedine K, Lim HW, Suzuki T, Katayama I, Hamzavi I, Lan CC, et al; Vitiligo Global Issue Consensus Conference Panelists. Revised classification/nomenclature of vitiligo and related issues: the Vitiligo Global Issues Consensus Conference. Pigment Cell Melanoma Res. 2012;25(3):E1-13.

3. Klatte LL, van der Beek N, Kemperman PM. 100 years of Wood's lamp revised. J Eur Acad Dermatol Venereol. 2015;29(5):842-7.

4. Parsad D. Mucosal vitiligo. In: Vitiligo [Internet]. Berlin, Heidelberg: Springer;2010. p.57-9. Available from: http://link.springer.com/10.1007/978-3540-69361-1_7

5. Gupta LK, Singhi MK. Wood's lamp. Indian J Dermatol Venereol Leprol. 2004;70(2):131-5.
6. Park KK, Brodell RT, Helms SE. Angular cheilitis, part 1: local etiologies Cutis. 2011;87(6):289-95.

7. Lane PM, Gilhuly T, Whitehead P, Zeng H, Poh CF, Ng S, et al. Simple device for the direct visualization of oral-cavity tissue fluorescence. J Biomed Opt. 2006;11(2):024006.

8. Andrade SA, Pratavieira S, Ribeiro MM, Bagnato VS, Pilla Varotti F. Oral cancer from the perspective of wide-field optical fluorescence: diagnosis, tumor evolution and post-treatment follow up. Photodiagnosis Photodyn Ther. 2017;19:239-42.

9. Shin D, Vigneswaran N, Gillenwater A, Richards-Kortum R. Advances in fluorescence imaging techniques to detect oral cancer and its precursors. Futur Oncol. 2010;6(7):1143-54.

10. Andrade SA, Pilla Varotti F, Bagnato VS, Pratavieira S. Firearm projectile in the maxillary tuberosity located by adjunctive examination of wide-field optical fluorescence. Photomed Laser Surg. 2018;36(2):112-5. 